\title{
HARDY-HILBERT'S INEQUALITY AND POWER INEQUALITIES FOR BEREZIN NUMBERS OF OPERATORS
}

\author{
Mubariz T. Garayev, Mehmet GÜrdal And ArZu OKUdAN
}

Abstract. We give operator analogues of some classical inequalities, including Hardy and HardyHilbert type inequalities for numbers. We apply these operator forms of such inequalities for proving some power inequalities for the so-called Berezin number of self-adjoint and positive operators acting on Reproducing Kernel Hilbert Spaces (RKHSs). More precisely, we prove that

$$
(\operatorname{ber}(f(A)))^{2} \leqslant C \operatorname{ber}\left((f(A))^{2}\right)
$$

for some constants $C>1$. We also use reproducing kernels technique to estimate $\operatorname{dist}(A, \mathscr{U})$, where $\mathscr{U}$ is the set of all unitary operators on a RKHS $\mathscr{H}=\mathscr{H}(\Omega)$ over some set $\Omega$, for some operator $A$ on $\mathscr{H}(\Omega)$.

Mathematics subject classification (2010): 47A63.

Keywords and phrases: Hardy inequality, Hardy-Hilbert inequality, Berezin symbol, Berezin number, positive operator, self-adjoint operator.

\section{REFERENCES}

[1] N. AronZajn, Theory of Reproducing Kernels, Trans. Amer. Math. Soc., 68, (1950), 337-404.

[2] N. DAS AND S. SAHOO, New inequalities of Hardy-Hilbert type, Bull. Acad. Ştinte Republ. Moldova. Mathematica, 63, (2010), 109-120.

[3] P. R. Halmos, A Hilbert Space Problem Book, Springer-Verlag, Berlin, 1982.

[4] F. HANSEn, Non-commutative Hardy inequalities, Bull. Lond. Math. Soc., 41, 6 (2009), 1009-1016.

[5] F. Hansen, K. KRulić, J. PeČArić And L.-E. Persson, Generalized noncommutative Hardy and Hardy-Hilbert type inequalities, Internat. J. Math., 21, 10 (2010), 1283-1295.

[6] G. Hardy, J. E. Littewood and G. Polya, Inequalities, 2nd ed. Cambridge University Press, Cambridge, 1967.

[7] M. T. KARAEV, Berezin symbol and invertibility of operators on the functional Hilbert spaces, J. Funct. Anal., 238, 1 (2006), 181-192.

[8] M. T. Karaev, Reproducing Kernels and Berezin Symbols Techniques in Various Questions of Operator Theory, Complex Anal.Oper. Theory, 7, 4 (2013), 983-1018.

[9] M. KiAn, Hardy-Hilbert type inequalities for Hilbert space operators, Ann. Funct. Anal., 3, 2 (2012), $128-134$.

[10] S. KILIÇ, The Berezin symbol and multipliers of functional Hilbert spaces, Proc. Amer. Math. Soc., 123, 12 (1995), 3687-3691.

[11] M. KRniĆ And J. PeČARIĆ, Extension of Hilbert's inequality, J. Math. Anal. Appl., 324, (2006), $150-160$.

[12] D. S. Mitrinović, J. E. PeČArić And A. M. Fink, Inequalities involving Functions and Their Integrals and Derivatives, Kluwer Academic Publishers, Boston, 1991.

[13] M. S. Moslehian, Operator extensions of Hua's inequality, Linear Algebra and its Applications, 430, 4 (2009), 1131-1139.

[14] E. Nordgren And P. Rosenthal, Boundary values of Berezin symbols, Oper. Theory: Advances and Applications, 73, (1994), 362-368. 
[15] D. D. Rogers, Approximation by unitary and essentially operators, Acta Sci. Math. (Szeged), 39, 1-2 (1977), 141-151.

[16] S. SAitoh, Theory of Reproducing Kernels and Its Applications, Pitman Research Notes in Mathematics Series, Longman Scientific\& Technical, UK, 189, 1988.

[17] S. Saitoh, D. Alpay, J. A. Ball and T. Ohsawa, Reproducing Kernels and Their Applications, Kluwer Academic Publishers, 1999.

[18] J. G. Stampfli, Minimal range theorem for operators with thin spectra, Pacif. J. Math., 23, (1967), 601-612.

[19] K. ZHU, Operator Theory in Function Spaces, Marcel Dekker, Ins., 1990. 